\title{
Crossing the Quality Chasm for Diabetes Care: The Power of One Physician, His Team, and Systems Thinking
}

\author{
Leif I. Solberg, MD, David H. Klevan, MD, and Stephen E. Asche, MA
}

Objective: To demonstrate that one physician can dramatically improve care of diabetes patients by taking a systems approach and getting support from leaders and other team members

Material and Methods: Pre-/postcomparison of quality measures for the diabetes patients of one primary care physician, compared with those of his entire large multi-specialty medical group. Working with a mentor and with clinic and medical group leaders, he established a clear goal, focused on a repeatable and important performance measure, and used repeated rapid cycle trials to make systems changes in care, with extensive task delegation to team members and emphasis on repeated testing and treatment intensification. The composite outcome measure requires that each diabetes patient meet all 5 of the following: $\mathrm{LDL}<100, \mathrm{HbA}_{1 \mathrm{C}}<7$, systolic blood pressure $<130$, regular aspirin use, and tobacco-free status.

Results: Over a 24-month period, quarterly measures for this physician's patients rose from $5.7 \%$ to $42.9 \%$, while the 7000 diabetes patients of the entire medical group only increased from $4.2 \%$ to $12.1 \%$. The change for those patients who stayed under his care for the entire period was even more dramatic-from $2.3 \%$ to $46.5 \%(P=<.0001)$. The largest improvements were for smoking documentation, aspirin use, and LDL control, with little change in $\mathrm{HbA}_{1 \mathrm{C}}$ levels.

Conclusion: One physician can accomplish a lot, if improvement is approached both systematically and persistently and if the work is coordinated with and supported by practice leaders. ( $\mathrm{J}$ Am Board Fam Med 2007;20:299-306.)

Diabetes is one of the most common and costly chronic conditions. Most patients with diabetes have multiple comorbidities, and the major source of the extensive morbidity and mortality is cardiovascular disease. ${ }^{1-3}$ Although there have been some improvements over the past 30 years, there is still much to do, with greater need to reduce cardiovascular risk factors than to improve glycemic control. ${ }^{4-7}$ It is now clear that the old model of education and exhortation will not be adequate to accomplish such broad-based and difficult improvements. Even the intermediate behavior change approaches demonstrated to have some effect in randomized trials, like measurement feed-

This article was externally peer-reviewed.

Submitted 8 August 2006; revised 30 October 2006; accepted 28 November 2006.

From the HealthPartners Research Foundation and HealthPartners Medical Group, Minneapolis, MN.

Funding: none.

Conflict of interest: none declared.

Corresponding author: Leif I. Solberg, MD, Health Partners Research Foundation, P.O. Box 1524, Mailstop 21111R, Minneapolis, MN 55440-1524 (E-mail: Leif.I.Solberg@HealthPartners.com). back, opinion leaders, disease management programs, and academic detailing, are unlikely to help very much. ${ }^{8-10}$ Instead, significant redesign of care that emphasizes team care, task delegation, a proactive population approach, facilitation of patient self-management, and extensive use of improved clinical information systems will be needed, similar to the components of the Chronic Care Model of Wagner and colleagues ${ }^{11-13}$ Perlin and Pogach ${ }^{14}$ have urged physicians to a higher standard-to review data and care processes, identify goals and strategies, develop action plans, track results, and get feedback.

However, clinicians tend to feel discouraged about their ability to improve diabetes care, often blaming patient nonadherence for low performance rates. ${ }^{15,16}$ Other clinician barriers include lack of time, simple oversight, lack of payment incentives, other clinical priorities in diabetic patients, other competing projects and priorities, lack of skills in diabetes management, concerns about drug side effects and costs, and discomfort with delegation of patient care. ${ }^{17-20}$ Clinicians also usually lack a sys- 
tem to routinely measure their performance on diabetes risk factors, so they don't know how well or poorly they are doing. ${ }^{21}$

When DHK first saw his personal rate for diabetes care in April of 2004, he was surprised and dismayed, both by how low it was and how indistinguishable it was from that of the medical group as a whole. Like most physicians, he had thought of himself as more competent than average, especially in diabetes care which was a common problem among his patients. He decided to try harder on his own, but his apparent small improvement in the next quarter's measure had evaporated by Q3, so he decided to take a more systematic approach to both care and the quality improvement process.

In fact, the story of DHK's comparative success is all the more impressive because it occurred in a medical group that has a long tradition of emphasizing quality and of improving diabetes care. The group's performance rates for diabetes and cardiovascular risk factor performance measures already put it in the top ranks both nationally and regionally. ${ }^{22,23}$ Over the past 10 years, the medical group has worked especially hard on improving diabetes care, achieving a mean $\mathrm{HbA}_{1 \mathrm{C}}$ level of 7.13 for all its diabetes patients in 2004. Nevertheless, his recent success has inspired the group to exert greater efforts and to use the systematic approaches he has demonstrated to be both feasible and effective.

\section{Methods}

\section{Context}

At the time of this study, this multispecialty medical group consisted of 600 physicians caring for about 300,000 patients in the Minneapolis-St. Paul metropolitan area. About two thirds of these patients had health insurance coverage with the health plan that also owned the medical group. The other one third had a variety of private and government coverage or no insurance. Overall, the patients had a racial/ethnic, educational, income, and age diversity similar to that of the area as a whole. Medical care for these patients was provided through a widely dispersed network of 24 primary care clinics, a relatively full range of specialty clinics, one owned and several contracted hospitals, and a variety of other care settings. Each primary care clinic, including that in which DHK worked, consisted of 3 to 15 primary care physicians of varying specialties, along with one to 2 nurse practitioners.
In 2004, the medical group took advantage of its newly implemented electronic medical record system to produce and report on quarterly measures of quality care for patients with diabetes at the level of individual physician, clinic, and medical group. $\mathrm{Al}$ though individual measures for diabetes care and cardiovascular risk factors were also collected for this report, the principal focus for measuring diabetes performance was on a composite measure called optimal diabetes control (ODC). This measure is focused on the extent to which each individual patient receives ideal care, which is defined by achieving target goals for LDL, HbA1c, systolic blood pressure, daily aspirin use, and tobacco-free status (see below). Since only those patients who have achieved all 5 targets are counted as success, it is both much more difficult to achieve high rates and a spur to comprehensive improvement. ${ }^{24}$ However, it is the measure that is now widely used throughout Minnesota and is the measurement approach used by the public reports of Minnesota Community Measurement. ${ }^{25}$

\section{Patient Sample}

The performance measure emphasized in this report (ODC) is reported quarterly for each physician, based on all each physician's patients with diabetes between ages 18 and 75 years who had had 2 primary care office visits during the most recent 12 months. During the period of this report, between 55 and 70 of DHK's diabetes patients fit this definition per quarter. This variation was mainly due to the requirement for having had 2 visits in the past year, but also due to patient death or movement among clinics and care systems. An ongoing cohort of 43 patients from these variably sized quarterly cross-sections was included in both Q1, 2004, and Q4, 2005. See Table 1 for the demographic and diabetes characteristics of these patients.

\section{Intervention}

The change process that DHK used for quality improvement was a variation of the Model for Improvement developed by Langley et al and popularized by Berwick and the Institute for Health care Improvement. ${ }^{26-28}$ This model suggests first answering 3 questions:

1. What are we trying to accomplish? 
Table 1. Characteristics of DHK's Patient Cohort as of March $2006(\mathrm{~N}=43)$

\begin{tabular}{|c|c|c|}
\hline Characteristic & $\mathrm{n}$ & Percentage \\
\hline \multicolumn{3}{|l|}{ Age (years) } \\
\hline $32-46$ & 5 & 12 \\
\hline $46-65$ & 27 & 63 \\
\hline $65-75$ & 11 & 26 \\
\hline Male & 28 & 65 \\
\hline \multicolumn{3}{|l|}{ Race/ethnicity } \\
\hline White & 33 & 77 \\
\hline Black & 3 & 7 \\
\hline Hispanic & 3 & 7 \\
\hline Asian & 3 & 7 \\
\hline Arabic & 1 & 2 \\
\hline Type II diabetes & 34 & 79 \\
\hline \multicolumn{3}{|c|}{ Comorbidities requiring hospitalization } \\
\hline Coronary disease & 9 & 21 \\
\hline Stroke & 4 & 9 \\
\hline Foot ulcer & 2 & 5 \\
\hline Heart failure & 2 & 5 \\
\hline \multicolumn{3}{|l|}{ Diabetes medications } \\
\hline Insulin & 20 & 46 \\
\hline Metformin & 21 & 49 \\
\hline Sulfonylurea & 17 & 40 \\
\hline Glitizone & 15 & 35 \\
\hline None & 1 & 2 \\
\hline \multicolumn{3}{|c|}{ Antihypertensive medications } \\
\hline 0 & 10 & 23 \\
\hline 1 & 8 & 19 \\
\hline 2 & 14 & 32 \\
\hline$>2$ & 11 & 26 \\
\hline \multicolumn{3}{|l|}{ Other medications } \\
\hline Statin & 32 & 74 \\
\hline Ezetimibe & 7 & 16 \\
\hline Other lipid types & 2 & 5 \\
\hline No lipid meds & 9 & 21 \\
\hline $\mathrm{ACE} / \mathrm{ARB}$ & 28 & 65 \\
\hline
\end{tabular}

2. How will we know that a change is an improvement? (by establishing a critical repeatable measure)

3. What changes can we make that will result in an improvement?

The model then proposes using small tests of change, using PDSA (Plan, Do Study, Act) in rapid cycles.

DHK wanted to achieve a level of diabetes care, using the ODC measure described above, of 50\% for his patients, a rate nobody thought possible in the near future. He knew that this would require systematic changes that involved extensive cooperation from others on his clinic team, but he wasn't sure what those changes should be. Therefore, he negotiated a regular monthly meeting with LIS, a quality improvement expert, had periodic conversations with diabetes experts in the medical group, and set to work. He had the advantage of already having both the quarterly performance measure and a list of his patients with diabetes, and he used small measurable tests of change to try a variety of systems changes in care. His initial chart review revealed several problems: patients did not have sufficiently frequent laboratory tests and office visits, insufficient medication changes were made during office visits, and there was little care delegation to others. The changes that he gradually found to be feasible, acceptable, and effective included the following:

1. Monthly measures of A1c, LDL, and blood pressure for individual patients until their goals were achieved

2. Equally frequent increases in their medication types and dosage as needed for control; borderline control was inadequate

3. Active outreach and follow-up (see nos. 4, 5, and 7)

4. Extensive use of other care team members through delegation and standing orders:

a. Receptionists sent letters, scheduled appointments, and reminded patients of lab tests

b. Rooming nurses ensured aspirin compliance and tobacco use documentation during and between office visits

c. Telephone RNs answered patient questions, ordered lab tests, and checked blood pressure

d. Pharmacist (blood pressure and lipid drugs) and diabetic nurse (diabetes drugs) facilitated medication changes per protocols already in place

5. Optimizing patient visits by obtaining tests beforehand and providing patients at visit end with a written summary of ODC progress, medication changes, desired tests, and plans

6. Activating and involving patients in self-management by improving their understanding of the importance of care goals and the methods needed to achieve them. A personalized letter was sent to each patient at the beginning of each quarter (after physician chart review) outlining ODC goals and the plan for tests and care 
7. A patient handout was created, listing ODC goals and providing information about common medications used for control of blood pressure, cholesterol, and A1c

8. Quarterly physician review of each patient's chart for adherence to the plan (cost $=4$ hours)

9. Above all, repeated emphasizing the importance and urgency of achieving optimal diabetes care to both staff and patients

\section{Analysis Approach}

As noted above, the principal measurement focus for the medical group and this report is the quarterly composite measure of ODC. To be counted in the numerator for this measure, each patient was required to have documentation of all the following:

- Most recent LDL level $<100 \mathrm{mg} / \mathrm{dL}$, measured within the past 12 months

- Most recent HbA1c level $<7$, measured within the past 6 months

- Systolic blood pressure (SBP) $<30$ at most recent clinic visit

- Current regular aspirin use (at least every other day)

- Current tobacco-free status at the most recent office visit

This also requires that patients have had these tests within the stated time windows, or they can only appear in the denominator, making it even harder to achieve high rates.

Overall ODC and its subcomponent rates were taken directly from medical group quarterly measurements. Chart audits were used to gather information about specific subgroups of DHK's patients (eg, those who left or were added to his measure over time). In addition, the clinic staff who had worked with DHK to provide the more systematic and proactive care were asked by a neutral third party who was not part of that clinic's staff to complete a brief survey (to get their honest perceptions of the tasks and patient reactions). Simple $\chi^{2}$ statistics were used to test the proportion comparisons for statistical significance. However, $\mathrm{McNe}$ mar's test was used in the cohort comparisons and an independent samples $t$ test was used to compare mean values between the independent samples of patients who were lost or added to the care of DHK during this time period.

\section{Results}

Table 1 describes the 43 patients who were consistently included in DHK's list of diabetes patients. All but one were 35 years of age or older, the majority were male, and they averaged 4 diabetes prescription medications. Nearly all had health insurance coverage. Over the time period of the study (2004 and 2005), there was much patient turnover. Of the 70 patients on DHK's list in the Q1 of 2004, 27 were not in the final cross-section at the end of 2005. Six had died, 8 changed care sites, 5 did not have the required 2 primary care visits in 2005 , and the other 8 were no longer eligible for the measure for a variety of reasons. Similarly, 27 of the final quarter's 70 patients were not in the initial group. The reasons for these added diabetics were similar: 14 had changed physicians to DHK, 7 lacked 2 visits in a year, 4 were newly diagnosed with diabetes, and 2 had newly moved to the area or gained health insurance.

The systematic changes described in the Methods section were added gradually, beginning in the middle of Q4 of 2004, so they only showed up fully in Q1 of 2005. DHK also had tried a variety of other changes earlier that had not proven to be feasible or effective. These included:

1. Working harder on his own

2. Emphasizing lifestyle changes (diet, weight loss, exercise) as part of all diabetes care plans, but these were insufficient to achieve the goals and had low adherence or persistence

3. Each care team member was assigned management of 6 diabetic patients, but this was excessively time consuming and could not be evaluated

4. Asking the diabetes nurse to manage a panel of patients by protocol worked well, but it was discontinued because it was not feasible for all physicians' patients

5. Registered nurses were asked to increase dosage or change medicines over the phone, using a DHK protocol or patient care plan, but they were uncomfortable with this new role

6. Changing prescription meds by letter or by phone resulted in less patient compliance than making the medication change during an office visit

Table 2 shows the change in the proportion of diabetes patients of DHK and of the entire medical 
Table 2. Percentage of Patients Achieving All ODC Goals Per Quarter $(n=7000$ for medical group, varying for DHK)

\begin{tabular}{|c|c|c|c|c|c|c|c|c|}
\hline \multirow[b]{2}{*}{ Patient Group } & \multicolumn{4}{|c|}{2004} & \multicolumn{4}{|c|}{2005} \\
\hline & Q1 & Q2 & Q3 & Q4 & Q1 & Q2 & Q3 & Q4 \\
\hline $\mathrm{n}$ & 70 & 63 & 69 & 67 & 56 & 55 & 62 & 70 \\
\hline DHK & 5.7 & 11.1 & 8.7 & 13.4 & 26.8 & 25.5 & 33.9 & 42.9 \\
\hline Medical group & 4.2 & 5.8 & 7.4 & 8.6 & 10.7 & 11.2 & 12.0 & 12.1 \\
\hline$P$ & .53 & .07 & .68 & .16 & .0001 & .0009 & $<.0001$ & $<.0001$ \\
\hline
\end{tabular}

group that achieved all the 5 ODC goals in each quarter during 2004 and 2005. It demonstrates the much greater improvement in the ODC measure for patients of DHK, although the medical group also showed some slow improvement over this time period. Table 3 shows the changes in each of the component measures in the ODC among patients of DHK between the beginning and end of the study period. The proportion of patients achieving each target improved by 13 to 37 percentage points, with the exception of HbA1c, which did not change significantly.

To determine whether this improvement was due to a change in patient mix or improved care, we examined the cohort of 43 patients that was present in both the baseline and final quarters. For this cohort, Table 4 shows that the increases for this group were only slightly larger than the overall cross-sections (19\% to $44 \%$ increases with again no change in HbA1c). To further clarify this picture, Table 5 compares some mean data for the 27 patients who were added to the data over the course of this study and the 27 who were lost to it at the time they left or entered the denominator group. These 2 groups' mean age and values for LDL, HbA1c, and blood pressure were statistically identical.

The clinic staff who participated most in this intervention included 2 receptionists, a rooming $\mathrm{LPN}$, an $\mathrm{RN}$, a pharmacist, and a diabetes educator. They all provided anonymous responses to a survey about their role in the program. Four reported spending only 1 to 2 hours per month on it, but the pharmacist and diabetes educator reported it was more like 12 hours because of extensive discussions and calls with patients. However, all rated its burden as a 1 to 3 (on a scale where 10 was severe burden) and its helpfulness to patients as an 8 to 10 (where 10 was very helpful). They reported most patients were satisfied and some were "quite impressed that we care enough to keep after them." However, a few patients had expressed some resentment about this aspect. All 6 were very pleased to be part of the effort, one described being proud of being involved and "that our patients are getting the best care possible." Another called it "a huge leap forward."

\section{Discussion}

This study shows that one physician can leap the quality chasm identified by the Institute of Medicine in a relatively short period (17 months). If Steiner $^{29}$ is correct, stories like this are valuable to health policy "to illustrate general issues through specific instances." Although the medical group overall improved its care of patients with diabetes threefold by the composite measure addressed here, DHK's patients improved sevenfold at the same time. Of course, this was clearly not a oneman effort. When DHK tried to work harder on his own, surprisingly little happened. It was only when he became more systematic and proactive, involving others in his team and clinic in the effort, that he achieved better results. His local team cer-

Table 3. Percentage of DHK's Patients Achieving Each Component of ODC Goals $(n=70$ in both quarters)

\begin{tabular}{lccccc}
\hline Quarter & LDL $<100$ & A1c $<7$ & BP $<130$ & Daily ASA & Tobacco Free \\
\hline 1 in 2004 & 46 & 53 & 71 & 59 & 56 \\
4 in 2005 & 75 & 50 & 83 & 96 & 91 \\
$P$ & .0008 & 0.72 & 0.11 & $<.0001$ & $<.0001$ \\
\hline
\end{tabular}

ODC, optimal diabetes control; LDL, low-density lipoproteins; BP, blood pressure. 
Table 4. Percentage of DHK's Patients Who Were Present Throughout the Study, Who Achieved ODC Goals (n = 43)

\begin{tabular}{lcccccc}
\hline Quarter & LDL $<100$ & A1c $<7$ & BP $<130$ & Daily ASA & Tobacco Free & All 5 \\
\hline 1 in 2004 & 42 & 46 & 65 & 56 & 56 & 2 \\
4 in 2005 & 79 & 54 & 84 & 100 & 91 & 46 \\
$P$ & .0006 & .37 & .045 & $<.0001$ & .0001 & $<.0001$ \\
\hline
\end{tabular}

ODC, optimal diabetes control; LDL, low-density lipoproteins; BP, blood pressure.

tainly seems to value this approach and it meant that his personal time for this effort could be minimal (1 to 2 hours per month). There is still work to be done, but DHK believes that much more improvement can still be done. It is now clear that improvement across a broad range of cardiovascular risk factors is more important to the health of patients with diabetes than simply improving diabetes control. ${ }^{1,30}$ Haffner et al ${ }^{1,3,31,32}$ have shown that about $70 \%$ of adults with diabetes die from a heart attack or stroke, and the effect of improved glycemic control (at least below an A1c level of 8) adds little to reducing these problems, compared with improving other cardiovascular risk factors. That is why this study as well as our medical group, health plan, and the regional medical community have all emphasized a composite measure for diabetes control that includes other major cardiovascular risk factors. Nolan and Berwick ${ }^{24}$ encouraged the same approach in a recent editorial.

Although this report demonstrates what one innovative and persistent physician can accomplish, it also emphasizes the importance of the types of care systems changes selected and the approach used to the change process. There is now extensive evidence that those systems changes that emphasize care delegation and population approaches are important. ${ }^{11,13,33-35}$ It is also clear that those changes need to be combined with a focus on overcoming

Table 5. Mean Values* for DHK's Patients Who Were Lost or Added to His Care (at the time of departure or arrival)

\begin{tabular}{lccccc}
\hline Group & $\mathrm{n}$ & LDL & A1c & BP & Age \\
\hline Lost & 27 & $98(2) \dagger$ & $6.8(4)$ & 120 & 62 years \\
Added & 27 & $91(3)$ & 7.7 & 118 & 59 years \\
$P$ & & .46 & .053 & .75 & .25 \\
\hline
\end{tabular}

* ASA and tobacco not included because status not well documented in 2004 for some of these patients.

$\uparrow$ Numbers in parentheses are for the number of patients with no measure available. clinical inertia (defined by Berlowitz et $\mathrm{al}^{36-38}$ as failure to intensify treatment of a patient who is not at their evidence-based goal). Berlowitz et al also have developed a quality measure for clinical inertia in diabetes care that compares the total treatment a patient receives to the level of treatment expected as a result of their diabetes control. Although such a measure was not available for our efforts, the approach taken emphasized overcoming inertia in medication changes in relation to frequent testing.

This project was also clearly aided by the electronic medical record (EMR). Useful EMR capabilities included easy data collection and access to the medical records of individual patients, facilitating sending frequent letters to patients, and providing for standing laboratory orders for LDL and A1c. Moreover, O'Connor has shown that in this same medical group, clinics that had the EMR well before others were no more successful in improving diabetes care. ${ }^{39}$ These improvement methods could be achieved without the EMR. A spreadsheet or separate chart could be maintained for diabetic patients and each patient not in optimum control could be scheduled for lab and clinician appointment each month until it was achieved. Patients who failed an appointment could be recurrently contacted and brief periodic paper chart audits could provide performance measures and feedback on success.

This example may also be important, though, in terms of identifying the conditions needed to achieve major improvements in a medical organization. Berwick has suggested that theory and research indicate that there are 3 major influences on the rate of diffusion of innovations within an organization: perceptions of the innovation, characteristics of the individuals who may adopt the change, and contextual and managerial factors. ${ }^{40} \mathrm{He}$ recommended that health care leaders "who want to accelerate the rate of diffusion of innovations within their organizations: find sound innovations, 
find and support "innovators," invest in "early adopters," make early adopter activity observable, trust and enable reinvention, create slack for change, and lead by example. Although we have yet to demonstrate that the work associated with DHK's example will lead to widespread diffusion in his medical group, it appears to meet most of the criteria Berwick has established.

As a quality improvement case study rather than a formal research project, this report clearly has limitations, including the inability to provide detailed data and reasons for the patients who left the care of DHK. We also have limited data on any coincident changes in quality measures for other conditions, which theoretically might have deteriorated while all this attention was devoted to diabetes. However, we do know that his performance on a variety of preventive services for all his patients did not deteriorate overall. Colorectal cancer screening and tobacco advice rates rose by $50 \%$ over these 2 years, while cholesterol, mammography, and Papanicolaou smear screenings all stayed about the same. Another limitation is that some of the improvement undoubtedly was from better documentation, especially since the electronic medical record was introduced in late 2004, although we believe that primarily affected smoking.

Postscript: During the review process for this article, we received the data from the Q1 and Q2 of 2006. It showed further improvement-DHK's patients increased from $42.9 \%$ in Q4 2005 to $45.3 \%$ and $52.5 \%$ in Q1 and Q2 of 2006, while there also was an improvement for the medical group, increasing from $12.1 \%$ to $13.7 \%$ and $15.4 \%(P<$ .0001 for comparisons within Q1 and Q2 of 2006).

We thank Brian Rank, MD, Medical Director of HealthPartners Medical Group, Steve Radosevich, MD, Chief of Professional Services at Como Clinic, and Rae Ann Williams, MD, Regional Assistant Medical Director, for support of the efforts of DHK to improve care within the context of overall organizational improvement. Special thanks to the team members at Como who contributed so much to the success of this approach. LIS consulted on the work, guided the data collection and analysis, and authored the article. DHK did the work, gathered some of the data, and helped revise the paper, and SEA did the statistical consulting and analysis and helped revise the paper.

\section{References}

1. Gilmer TP, O'Connor P J, Rush WA, et al. Predictors of health care costs in adults with diabetes. Diabetes Care 2005;28:59-64.

2. Brun E, Nelson RG, Bennett PH, et al. Diabetes duration and cause-specific mortality in the Verona Diabetes Study. Diabetes Care 2000;23:1119-23.

3. O'Connor PJ, Spann SJ, Woolf SH. Care of adults with type 2 diabetes mellitus. A review of the evidence. J Fam Pract 1998;47(5 Suppl):S13-S22.

4. Imperatore G, Cadwell BL, Geiss L, et al. Thirtyyear trends in cardiovascular risk factor levels among US adults with diabetes: National Health and $\mathrm{Nu}-$ trition Examination Surveys, 1971-2000. Am J Epidemiol 2004;160:531-9.

5. Fox CS, Coady S, Sorlie PD, et al. Trends in cardiovascular complications of diabetes. JAMA 2004; 292:2495-9.

6. Egede LE, Zheng D. Modifiable cardiovascular risk factors in adults with diabetes: prevalence and missed opportunities for physician counseling. Arch Intern Med 2002;162:427-33.

7. Saaddine JB, Cadwell B, Gregg EW, et al. Improvements in diabetes processes of care and intermediate outcomes: United States, 1988-2002. Ann Intern Med 2006;144:465-74.

8. Keating NL, Landrum MB, Landon BE, et al. The influence of physicians' practice management strategies and financial arrangements on quality of care among patients with diabetes. Med Care 2004;42: 829-39.

9. Glasgow RE, Nutting PA, King DK, et al. Randomized effectiveness trial of a computer-assisted intervention to improve diabetes care. Diabetes Care 2005;28:33-9.

10. Kiefe CI, Allison JJ, Williams OD, Person SD, Weaver MT, Weissman NW. Improving quality improvement using achievable benchmarks for physician feedback: a randomized controlled trial. JAMA 2001;285:2871-9.

11. Bodenheimer T, Wagner EH, Grumbach K. Improving primary care for patients with chronic illness. JAMA 2002;288:1775-9.

12. Bodenheimer T, Wagner EH, Grumbach K. Improving primary care for patients with chronic illness: the chronic care model, Part 2. JAMA 2002; 288:1909-14.

13. O'Connor PJ, Sperl-Hillen JM, Pronk NP, Murray T. Primary care clinic-based chronic disease care: features of successful programs. Dis Manage Health Outcomes 2001;9:691-8.

14. Perlin JB, Pogach LM. Improving the outcomes of metabolic conditions: managing momentum to overcome clinical inertia. Ann Intern Med 2006;144: $525-7$.

15. O'Connor PJ. Patient archetypes, physician archetypes, and tailored diabetes care. J Am Board Fam Pract 2002;15:334-7.

16. Helseth LD, Susman JL, Crabtree BF, O'Connor PJ. Primary care physicians' perceptions of diabetes management. A balancing act. J Fam Pract 1999;48: $37-42$.

17. Bodenheimer T, Wang MC, Rundall TG, et al. 
What are the facilitators and barriers in physician organizations' use of care management processes? Jt Comm J Qual Saf 2004;30:505-14.

18. Hiss RG. Barriers to care in non-insulin-dependent diabetes mellitus. The Michigan experience. Ann Intern Med 1996;124(1 Pt 2):146-8.

19. Larme AC, Pugh JA. Evidence-based guidelines meet the real world: the case of diabetes care. Diabetes Care 2001;24:1728-33.

20. Streja DA, Rabkin SW. Factors associated with implementation of preventive care measures in patients with diabetes mellitus. Arch Intern Med 1999;159: 294-302.

21. Berwick DM, James B, Coye MJ. Connections between quality measurement and improvement. Med Care 2003;41(1 Suppl):I30-I38.

22. Sperl-Hillen J, O'Connor PJ, Carlson RR, et al. Improving diabetes care in a large health care system: an enhanced primary care approach. Jt Comm J Qual Improv 2000;26:615-22.

23. Sperl-Hillen JM, O'Connor PJ. Factors driving diabetes care improvement in a large medical group: ten years of progress. Am J Manag Care 2005;11(5 Suppl):S177-S185.

24. Nolan T, Berwick DM. All-or-none measurement raises the bar on performance. JAMA 2006;295: 1168-70.

25. Amundson GM, Frederick J. Making quality measurement work. Minn Med 2003;86:50-2.

26. Berwick DM. Developing and testing changes in delivery of care. Ann Intern Med 1998;128:651-6.

27. Langley GJ, Nolan KM, Nolan TW. The foundation of improvement. Qual Prog 1994;27:81-6.

28. Langley GJ, Nolan KM, Nolan TW, Norman CL, Provost LP. Improvement guide: a practical approach to enhancing organizational performance. San Francisco: Jossey-Bass; 1996.

29. Steiner JF. The use of stories in clinical research and health policy. JAMA 2005;294:2901-4.
30. O'Connor PJ. Commentary: improving diabetes care by combating clinical inertia. Health Serv Res 2005;40(6 Pt 1):1854-61.

31. Savage PJ, Narayan KM. Reducing cardiovascular complications of type 2 diabetes. A complex but achievable and affordable task. Diabetes Care 1999; 22:1769-70.

32. O'Connor PJ. Setting evidence-based priorities for diabetes care improvement. Int J Qual Health Care 2003;15:283-5.

33. Ofman JJ, Badamgarav E, Henning JM, et al. Does disease management improve clinical and economic outcomes in patients with chronic diseases? A systematic review. Am J Med 2004;117:182-92.

34. Fireman B, Bartlett J, Selby J. Can disease management reduce health care costs by improving quality? Health Aff (Millwood) 2004;23:63-75.

35. Solberg LI, Kottke TE, Conn SA, Brekke ML, Calomeni CA, Conboy KS. Delivering clinical preventive services is a systems problem. Ann Behav Med 1997; 19:271-8.

36. Berlowitz DR, Ash AS, Glickman M, et al. Developing a quality measure for clinical inertia in diabetes care. Health Serv Res 2005;40(6 Pt 1):1836-53.

37. O'Connor PJ. Overcome clinical inertia to control systolic blood pressure. Arch Intern Med 2003;163: 2677-8.

38. O'Connor PJ, Sperl-Hillen JM, Johnson PE, Rush WA, Biltz G. Clinical inertia and outpatient medical errors. In: Henriksen K, Battles J, Lewin D, Marks $\mathrm{E}$, eds. Advances in patient safety: From research to implementation. Rockville, MD: Agency for Healthcare Research and Quality; 2005. p. 293-308.

39. O'Connor PJ, Crain AL, Rush WA, Sperl-Hillen JM, Gutenkauf JJ, Duncan JE. Impact of an electronic medical record on diabetes quality of care. Ann Fam Med 2005;3:300-6.

40. Berwick DM. Disseminating innovations in health care. JAMA 2003;289:1969-75. 